\title{
Influence of Benzoate on Substituent Benzoic Acids with Implications on Spectroscopic Studies through Inter Molecular Hydrogen Bonding
}

\author{
Ch.Ravi Shankar Kumar \\ Department of Physics, Institute of Science, GITAM University, Visakhapatnam, India. \\ Email: rskchaval@gmail.com
}

Received March 11 ${ }^{\text {th }}, 2011$; revised April 20 ${ }^{\text {th }}, 2011$; accepted May 20 ${ }^{\text {th }}, 2011$.

\begin{abstract}
Comprehensive study on the homologous series of compounds in the form A-R-HHB are synthesized with central rigid core as benzoic acids together with substituent's alkoxy $(A)$ and alkyl $(R)$ group of equal chain lengths from 5 to 10 are connected to hexyl-p-hydroxy benzoate (HHB). These complexes form supramolecular structures by self assembling process due to intermolecular hydrogen bonding. The formation is analyzed with techniques involving polarizing optical microscope, infrared spectroscopy, proton NMR spectroscopy and powdered X-ray diffraction. Results suggest that complexes arise from both $A$ and $R$ groups exhibit enantiotropic layered texture of crystal G phase observed by microscopic studies due to flexible nature of mesogenics. The conversion of free to molecular complexes is determined with variations in spectral shifts between its terminal groups $\mathrm{COOH}$ and $\mathrm{OH}$ of molecules involving inter molecular hydrogen bonding and its bonding index by FTIR spectra. The changes in structure and dynamics due to hydrogen bonding in complexes are convinced by proton NMR spectra with chemical shifts in specified range. The defects in crystal structure responsible for enantiotropic phenomena are analyzed by powdered X-ray diffraction.
\end{abstract}

Keywords: Phase Transitions, Microscopy, IR Spectra and Hydrogen Bonding

\section{Introduction}

Over the past decades the design and synthesis of new liquid crystalline molecules [1] has considerably broadened mesophase stability [2] especially with rod like molecules due to intermolecular interactions $[3,4]$ that play vital role in the formation of liquid crystal textures [5]. These organized structures are built by strategic units leading to supramolecular structures [6,7] enable meaningful relationship cutting across its entities with their functional relationships attributed involves hydrogen bonding [8]. Liquid crystals possess fluid like properties are greatly influenced with non mesogenics stems the interaction leading to structural variations by self assembling [9-13] process that greatly influence the physical properties due to defects that exist in solid state where individual displacements of atoms are suppressed. The substituent liquid crystals or mesogenics exhibiting nematics under consideration are perfectly rigid $[8,11,14]$ when associated with addition of benzoate (HHB) results with deviation in structure that occur due interaction between molecules. Many investigations lead to the forma- tion of supramolecular structures due to hydrogen bonding due to its stability $[2,15]$ and directionality that significantly change the molecules has drawn attention in development of new structures. In the present work mesomorphic properties [16] emphasized in terms of its features in normal state between hexyl-p-hydroxy benzoate and substituent liquid crystals A [17] and R [18] through hydrogen bonding as illustrated in Figure 1.

\section{Experimental}

The two mesogenics [19] that were chosen for conduct of experimental studies include the p- $n$-alkoxy benzoic acid (A), p- $n$-alkyl benzoic acid (R) and non mesogenic hexylp-hydroxy benzoate (HHB) are purchased from Frinton laboratories New Jersey, USA. These compounds possess a number of favorable properties in studies involving both crystalline and anisotropic states. The preparation is performed by dissolving in 1:1 ratio the compounds in pyridine under constant stirring for about 4 hours approximately at $80^{\circ} \mathrm{C}$ and the clear solution is obtained. The solvent was removed by fractional distillation with 
resultant mixture was dried and re-crystallized by using dichloro-methane.

The phase transition temperatures and texture studies of synthesized materials were studied using Hertel Reuss super-pan II polarizing optical microscope (POM) equipped with optical display (DP10) at scan rate of $0.1^{\circ} \mathrm{C} / \mathrm{min}$. The liquid state (chloroform) and solid state $(\mathrm{KBr})$ FT-IR-spectra were recorded on Perkin-Elmer (spectrum bX) series at room temperature from 400 $4400 \mathrm{~cm}^{-1}$ with resolution $8 \mathrm{~cm}^{-1}$. The proton nuclear magnetic resonance $\left({ }^{1} \mathrm{H}\right.$ NMR) spectra were recorded on the Brucker Avance $400 \mathrm{MHz}$ instrument in $\mathrm{CDCL}_{3}$ with chemical shifts in ppm. X-ray studies were performed at room temperature using Phillips powdered XRD system in determining crystalline parameters.

\section{Results and Discussions}

Liquid crystals show unusual behavior due to variations in temperature. The transitions from crystalline to isotropic and back occur in single step in both heating and cooling process. Textures observed by polarizing optical microscope obtained in heating are much difficult to assign as they are complicated and natural textures in cooling are significant, of substituent's A and R and its complexes A-R-HHB are listed in Table 1. Realization of complexes by self assembling lead to supramolecular structures possess mechanical properties better than conventional liquid crystals by extending its flexible ends [1921] with benzoate that gained positional order with layered texture of crystal G phase as illustrated in Figure 2.

This phase has molecules packed in layers with their long axis tilted with respect to normal to layer planes with tilt molecules performing reorientational motion about long axes that contributes to hexagonal symmetry A consequence of transition temperatures of the free and complexes is that oriertational textures with long axes of molecules perpendicular to glass substrate involve higher transition temperatures than layered textures where long axes are at an angle with glass substrate. The transition temperatures are plotted against chain length are illustrated in Figure 3. The lowered nature of temperatures is an implication of lose in rigidity, reducing fluidity and change in symmetry of free molecules due to participation of flexible ends with benzoates with thermal span lesser by $8^{\circ} \mathrm{C}$. A feature in transition temperatures of molecular complexes associates contrast behavior in members of substituent's A and partial even odd effect [22] with $\mathrm{R}$ group that reveal the length of flexible terminals had influenced in occurrence of the said phase.

The Fourier transform infrared spectral interpretation [23-25] is used in exploiting the structural defects responsible for change in orientation is realized with spectral shifts $\left(\mathrm{cm}^{-1}\right)$ due to hydrogen bonding $(\mathrm{OH})$ of substituent's and its complexes are listed in Table 2. The solid state spectral studies reveal $\mathrm{OH}$ of $\mathrm{A}$ and $\mathrm{R}$ groups is much less in comparison with HHB indicating their intact nature. On complexation there is tremendous change in spectral shifts of complexes A-R-HHB formed with $A$ are contrary with $\mathrm{R}$ group. On structural level these shifts enabled terminal groups of aromatic rings to participate in hydrogen bonding that has nucleated in formation of layered texture.

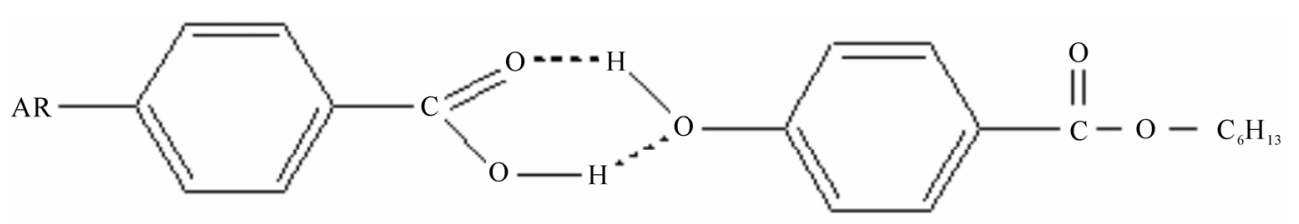

Figure 1. Bonded structure of substituted benzoic acid with hexyl-p-hydroxy benzoate.

Table 1. Polarizing optical microscope studies of free and complexes.

\begin{tabular}{cccccccc}
\hline \multirow{2}{*}{ Chain Length } & \multicolumn{3}{c}{ Type of texture } & \multicolumn{5}{c}{ Transition Temperatures ${ }^{\circ} \mathrm{C}$} \\
\cline { 2 - 7 } & A & R & (A-R-HHB) & A & R & (A-R-HHB) $)_{\text {A }}$ & $(\text { A-R-HHB })_{\mathrm{R}}$ \\
\hline 5 & $\mathrm{~N}$ & $\mathrm{~N}$ & $\mathrm{G}$ & 151.4 & 124 & 98.4 & 96 \\
6 & $\mathrm{~N}$ & $\mathrm{~N}$ & $\mathrm{G}$ & 153.8 & 112.5 & 85 & 71 \\
7 & $\mathrm{~N}$ & $\mathrm{~N}$ & $\mathrm{G}$ & 146.8 & 121.7 & 80 & 83.5 \\
8 & $\mathrm{~N}$ & $\mathrm{~N}$ & $\mathrm{G}$ & 147.5 & 110.3 & 85.7 & 83 \\
9 & $\mathrm{~N}$ & $\mathrm{~N}$ & $\mathrm{G}$ & 142.9 & 115.8 & 87.2 & 83 \\
10 & $\mathrm{~N}$ & $\mathrm{~N}$ & $\mathrm{G}$ & 138.3 & 108.8 & 90.6 & 81.4 \\
\hline
\end{tabular}




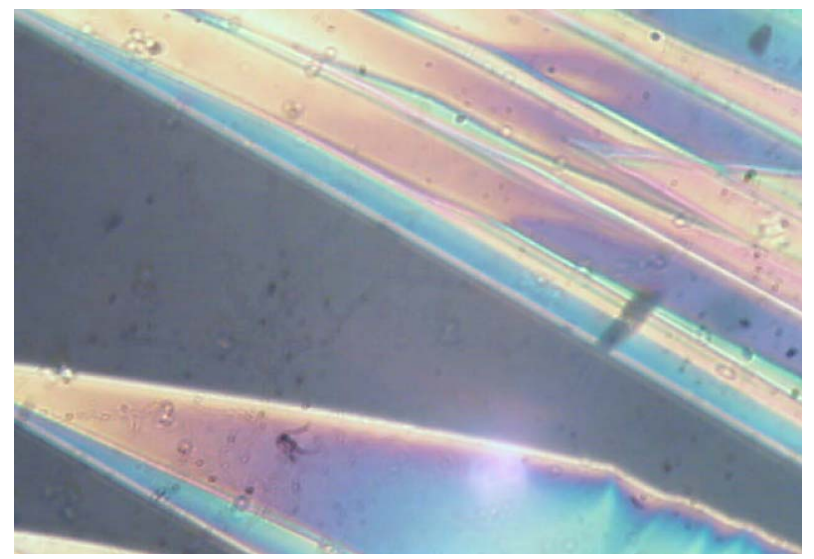

Figure 2. Texture of crystal G phase.

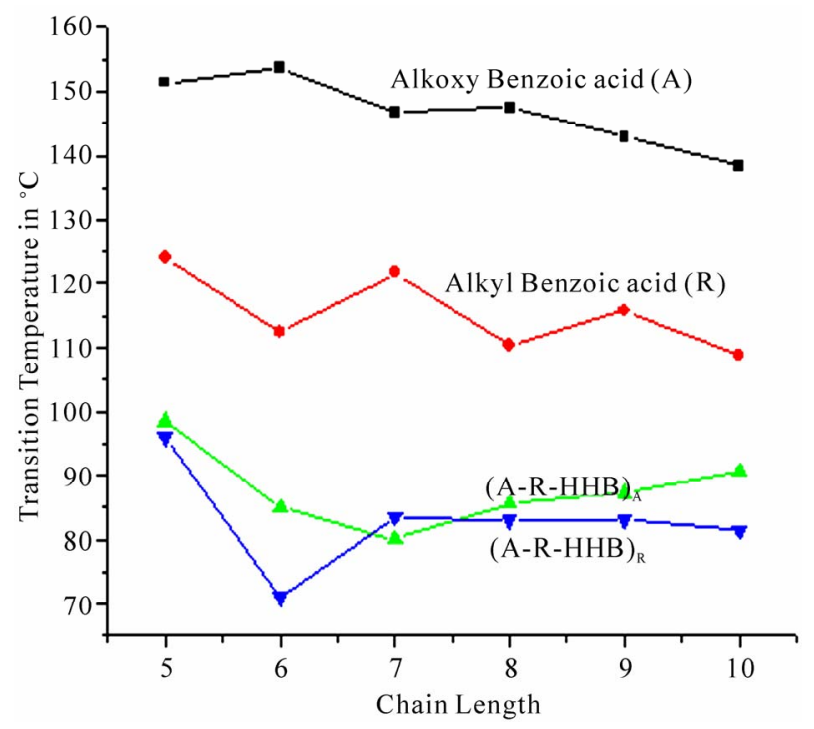

Figure 3. Plot of transition temperatures vs chain length.

Coordinating the absorption studies from FTIR spectra of substituent's and complexes in determination of hydrogen bonding index $[26,27]$ responsible for altered texture are listed in Table 3 . These absorption studies reveal even odd behavior in substituent groups $A$ and $R$ that is lost on complexation with benzoate. The studies involving hydrogen bonding index determines the extent of participation between the molecules that increases slowly in chain length with A group due to paramorphosis and an even odd behavior associates with $\mathrm{R}$ group. These variations signify that flexible terminals of both groups influenced the occurrence of phase due to dispersed non covalent interaction.

The studies of complexes with NMR spectra [28] provide rich structure and dynamic information that is lost due to its swift averaging in the liquid phase. Chemical shifts provide the first signature to understand the pack- ing and hydrogen bonding formation [29] in the solid state. The ${ }^{1} \mathrm{H}$ NMR spectra of the free and its complexes exhibit different regions are well resolved in the spectrum. The structural studies for complexes indicate chemical shifts around 0.9 attributed to the $\mathrm{CH}_{3}$, multiplets in range $1.3-1.8$ attributes to $\left(\mathrm{CH}_{2}\right)_{\mathrm{n}}$ of both the groups and 4.3 triplet for bonded $\mathrm{OH}$. The shifts at 6.9 7.0 contribute to aromatic protons. The $\mathrm{OH}$ of phenolic is assigned to 8.2 suggests the down field shift due to inter molecular hydrogen bonding These chemical shifts reveal the convinced IR with peak around $680-730 \mathrm{~cm}^{-1}$.

Finally with X-ray diffraction [30] involving small angle regions reveal the information of the anisotropic properties between parallel and perpendicular incident directions. These properties arise due to defects existing in solid state which are the crystalline parameters determined in angstrom units (AU) are listed in Table 4.

The inter planar spacing $d=n \lambda / \sin \theta$, the thickness $(t)=$ $0.94 \lambda /\left(B \cos \theta_{B}\right)$ are determined with $\lambda=1.54056$ angstroms units, $(B)$ is full width half maximum and $\theta_{B}$ is bragg angle. The studies reveal drastic change in intensity, interplanar spacing and thickness irrespective of the substituent group in comparison with the benzoate. The influence of functional molecules is integrated into system by involving the crystalline properties for the obtained texture with reduced scattering. The choice of benzoate enabled in generation of new molecular structure that helped to expand the properties of liquid crystals that arise from aromatics due to displaced center of gravities with increased variation in size and planar separation.

With increase in chain length the influence of benzoate on the core molecule enabled greater degree of conformational freedom [31,32]. These parameters articulate that the benzoate group has successfully disturbed the oriented texture of its molecules to layered texture.

\section{Conclusions}

The work resulted in influence of benzoate successfully leading with enantiotropic layered texture in both alkoxy and alkyl groups. The disturbed symmetry with reduced transition temperatures gained positional order by self assembling process. The hydrogen bonding with narrow peaks and enhanced shifts lead the aromatic rings to nucleate its structure together with bonding index has increased molecular packing. The liquid crystal on complexation with benzoate has lead to new molecular and supramolecular structure with properties that are dependent of aromatics that are mesogens. The explanation is valid with necessary support in altering the texture and its confirmation with various techniques due to hexyl- $p$ hydroxy benzoate and further studies in control of self assembling process need to be performed. 
Table 2. Solid state IR spectra.

\begin{tabular}{cccccc}
\hline Chain Length & $(\mathrm{OH})_{\mathrm{A}}$ & $(\mathrm{OH})_{\mathrm{R}}$ & $(\mathrm{OH})_{\text {Hнв }}$ & $(\mathrm{A}-\mathrm{R}-\mathrm{HHB})_{\mathrm{OHA}}$ & $(\mathrm{A}-\mathrm{R}-\mathrm{HHB})_{\mathrm{OHR}}$ \\
\hline 5 & & & 3374 & & \\
6 & 2955 & 2958 & & 3300 & 3294 \\
7 & 2933 & 3120 & 3435 & 3439 \\
8 & 2932 & 2926 & 3441 & 3297 \\
9 & 3130 & 2926 & 3399 & 3295 \\
10 & 2924 & 2924 & 3412 & 3440 \\
\hline
\end{tabular}

Table 3. Hydrogen bonding index.

\begin{tabular}{ccccccc}
\hline Chain Length & $(\mathrm{OH})_{\mathrm{A}}$ & $(\mathrm{OH})_{\mathrm{R}}$ & $(\mathrm{A}-\mathrm{R}-\mathrm{HHB})_{\mathrm{A}}$ & $(\text { Bonding index })_{\mathrm{A}}$ & $(\text { A-R-HHB })_{\mathrm{R}}$ & $(\text { Bonding index })_{\mathrm{R}}$ \\
\hline 5 & 65.76 & 19.93 & 14.56 & 0.221 & 20.67 & 1.037 \\
6 & 28.07 & 70.07 & 30.89 & 1.100 & 24.1 & 0.343 \\
7 & 72.19 & 19.38 & 84.77 & 1.174 & 26.20 & 1.351 \\
8 & 35.07 & 37.47 & 69.04 & 1.968 & 26.76 & 0.714 \\
9 & 37.26 & 11.75 & 91.72 & 2.461 & 21.75 & 1.851 \\
10 & 33.07 & 16.75 & 96.6 & 2.9210 & 25.10 & 1.498 \\
\hline
\end{tabular}

Table 4. Crystalline parameters.

\begin{tabular}{|c|c|c|c|c|}
\hline Name of Compound & Bragg angle & Intensity & Interplanar distance & Thickness \\
\hline НHB & 22.657 & 224 & 3.999 & 0.0767 \\
\hline \multicolumn{5}{|l|}{$(\mathrm{A}-\mathrm{R}-\mathrm{HHB})_{\mathrm{A}}$} \\
\hline 5 & 20.053 & 473 & 4.4918 & 0.765 \\
\hline 6 & 23.008 & 789 & 3.9407 & 3.7004 \\
\hline 7 & 14.194 & 2731 & 6.2828 & 1.829 \\
\hline 8 & 20.024 & 1146 & 4.499 & 0.7356 \\
\hline 9 & 9.577 & 148 & 9.258 & 0.0394 \\
\hline 10 & 4.449 & 98 & 19.86 & 0.3800 \\
\hline \multicolumn{5}{|l|}{$(\mathrm{A}-\mathrm{R}-\mathrm{HHB})_{\mathrm{R}}$} \\
\hline 5 & 12.285 & 582 & 7.2404 & 1.1013 \\
\hline 6 & 22.810 & 201 & 3.9738 & 0.1707 \\
\hline 7 & 19.103 & 962 & 4.7074 & 0.9529 \\
\hline 8 & 22.916 & 465 & 3.9564 & 1.0308 \\
\hline 9 & 12.596 & 949 & 7.0643 & 0.65758 \\
\hline 10 & 22.289 & 7157 & 4.0614 & 0.2154 \\
\hline
\end{tabular}




\section{Acknowledgements}

The author thanks the Management of GITAM University for its support in pursuing the work and especially Dr.Trimurthulu for recording the Spectra and CIL University of Hyderabad in providing powdered X-ray diffraction facility.

\section{REFERENCES}

[1] J. W. Goodby, "Editorial-Liquid Crystals," Chemical Society Reviews, Vol. 36, No. 12, 2007, pp. 1855-1856.

[2] T. Kato and J. M. J. Frechet, "A New Approach to Mesophase Stabilization through Hydrogen Bonding Molecular Interactions in Binary Mixtures," Journal of the American Chemical Society, Vol. 111, No. 22, October 1989, pp. 8533-8534. doi:10.1021/ja00204a044

[3] J. W. Xu, C. B. He, K. C. Toh and X. H. Lu, "Intermolecular Interaction in Multicomponent Supramolecular Com- plexes through Hydrogen-Bonding Association,” Macro- molecules, Vol. 35, No. 23, November 2002, pp. 8846- 8851.

[4] S. Machida, H. Hirai, T. Kawamura, Y. Yamamoto and T. Yagi, "Structural Changes and Intermolecular Interactions of Filled Ice LC Structure for Hydrogen Hydrate under High Pressure," Journal of Physics: Conference Series, Vol. 215, No. 1, March 2010, pp. 1-7. doi:10.1088/1742-6596/215/1/012060

[5] G. W. Gray and G. By, "Smectic Liquid Crystals," Leonard Hill Press, London, 1984.

[6] G. R. and Desiraju, "Hydrogen Bonds and Other Intermolecular Interactions," Journal of the Chemical Society, No. 21, 2000, pp. 3745-3751.

[7] L. M. Wilson, “A Highly Ordered Hydrogen Bonded Network,” Liquid Crystals, Vol. 18, No. 3, 1995, pp. 381-385. doi:10.1080/02678299508036635

[8] J. W. Xu, C. L. Toh, X. M. Liu, et al., "Synthesis and Self Assembly of Donar-Spacer-Acceptor Molecules. Liquid Crystals Formed by Single Component Complexes via Intermolecular Hydrogen Bonding Interactions,” Macromolecules, Vol. 38, No. 5, March 2005, pp. 1684-1690. doi:10.1021/ma047999l

[9] Y. M. Huang, "Self Assembled Optical Gratings with Banana Liquid Crystals,” Key Engineering Materials, Vol. 428-429, January 2010, pp. 12-23. doi:10.4028/www.scientific.net/KEM.428-429.12

[10] J. A. A. W. Elemans, et al., "The Development of Self-Assembled Liquid Crystal Display Alignment Layers," Philosophical Transactions of the Royal Society A, Vol. 365, No. 1855, 2007, pp. 1553-1576.

[11] T. J. Dingemans, L. A. Madsen, et al., "Uniaxial and Biaxial Nematic Liquid Crystals," Philosophical Transactions of the Royal Society A. Vol. 364, No. 1847, 2006, pp. 2681-2696. doi:10.1098/rsta.2006.1846

[12] J. M. Lehn, "Supramolecular Chemistry-Scope and Per- spectives Molecules, Supermolecules, and Molecular Devices (Nobel Lecture)," Angewandte Chemie International Edition, Vol. 27, No. 1, January1988, pp. 89-112. doi:10.1002/anie.198800891

[13] K. Tanabe and T. Kato, "Self-Assembly of Cyclobis (Paraquat-p-Phenylene)s," Chemical Communications, No. 14, 2009, pp. 1864-1866.

[14] M. Kimura, et al., "Self-Assembly of Liquid Crystalline Triphenylene-Oligo(Ethylene Oxide)-Triphenylene Molecules and Their Complexes with Lithium Triflate," Liquid Crystals, Vol. 34, No. 1, 2007, pp. 107-112. doi:10.1080/02678290601036142

[15] T. Kato, et al., "Hydrogen-Bonded Liquid Crystals Built from Hydrogen-Bonding Donors and Acceptors Infrared Study on the Stability of the Hydrogen Bond between Carboxylic Acid and Pyridyl Moieties," Liquid Crystals, Vol. 33, No. 11-12, 2006, pp. 1429-1437. doi:10.1080/02678290601119807

[16] K. Kubo, et al., "Synthesis, Crystal Structure and Mesomorphic Properties of Liquid Crystals with a Bis (Tropon-2-yl)-4,4'-Azobisbenzoate Core," Journal of Oleo Science, Vol. 54, No. 3, February 2005, pp. 179-183. doi:10.5650/jos.54.179

[17] P. Swathi, P. A. Kumar and V. G. K. M. Pisipati, "Induced Crystal G Phase through Intermolecular Hydrogen Bonding II. Influence of Alkyl Chain Length of n-Alkyl p-Hydroxybenzoates on Thermal and Phase Behavior," Liquid Crystals, Vol. 27, No. 5, 2000, pp. 665-669. doi:10.1080/026782900202525

[18] Ch. R. S. Kumar, et al., "Formation of Crystal G Phase in Hydrogen Bonded Mesogen Constructed by p-n-Alkyl Benzoic Acid with Ortho - Toulamide,” International Journal of Modern Physics B, Vol. 23, No. 14, June 2009, pp. 3187-3194.

[19] G. R. Luckhurst, “A Missing Phase Found at Last,” Nature, Vol. 430, No. 6998, 2004, pp. 413-414.

[20] M. Saminathan and C. K. S. Pillai, "Thermotropic Side Chain Polyacrylates with Azobenzene Mesogenic Groups: Synthesis and Thermal Behaviour," Macromolecular Chemistry and Physics, Vol. 201, No. 17, November 2000, pp. 2475-2483. doi:10.1002/1521-3935(20001101)201:17<2475::AID-M ACP2475>3.0.CO;2-T

[21] T. Kajitani, et al., "Liquid Crystalline Amides: Linear Arrangement of Rod-Like Molecules by Lateral Intermolecular Hydrogen Bonding and Molecular Shape Effect," Journal of Materials Chemistry, Vol. 14, No. 23, 2004, pp. 3449-3456. doi:10.1039/b408672d

[22] R. W. Lenz, et al., "Synthesis and Properties of Thermotropic Compounds with Two Terminal Mesogenic Units and a Central Spacer III. Homologous Series of $\alpha$, $\omega$-Bis[4-(p-nitrobenzoyloxy) phenoxy]Alkanes," Bulletin of Korean Chemical Society, Vol. 4, No. 4, April 1983, pp. 176-180.

[23] R. M. Silverstein, et al., "Spectrometric Identification of Organic Compounds," 6th Edition, John Wiley \& Sons 
Canada, Ltd., Toronto, 2005.

[24] M. S. C. Flett, "Characteristic Frequencies of Chemical Groups in the Infra-Red,” Elsevier Publishing Company, London, 1963.

[25] J. Coates, "Interpretation of Infrared Spectra, a Practical Approach,” John Wiley \& Sons, Hoboken, 2000.

[26] X. Dai, et al., "Study on Structure and Orientation Action of Polyurethane Nanocomposites,” Macromolecules, Vol. 37, No. 15, July 2004, pp. 5615-5623. doi:10.1021/ma049900g

[27] C. B. Wang and S. L. Cooper, "Morphology and Properties of Segmented Polyether Polyurethaneureas," Macromolecules, Vol. 16, No. 5, May 1983, pp. 775-786. doi:10.1021/ma00239a014

[28] F. Scheinmann, "An Introduction to Spectroscopic Methods for Identification of Organic Compounds," Pergamon Press, Oxford, 1970.
[29] A. Bruck, et al., "Hydrogen Bonds in Carboxylic Acid-Carboxylate Systems in Solution. 1. In Anhydrous, Aprotic Media,” Organic Letters, Vol. 2, No. 14, 2000, pp. 2007-2009.

[30] B. D. Cullity and S. R. Stock, "Elements of X-Ray Diffraction,” 3rd Edition, Prentice Hall Publishers, Upper Saddle River, 2001.

[31] M. Engelhardt, “Choreography for Nucleosomes: The Conformational Freedom of the Nucleosomal Filament and Its Limitations," Nucleic Acids Research, Vol. 35, No. 16, August 2007, p. e106. doi:10.1093/nar/gkm560

[32] L. Tracy, et al., "Supramolecular Isomerism in Coordination Polymers: Conformational Freedom of Ligands in $\left[\mathrm{Co}\left(\mathrm{NO}_{3}\right)_{2}(1,2-\text {-bis(4-Pyridyl) Ethane })_{1.5}\right]_{\mathrm{n}}$," Angewandte Chemie International Edition in English, Vol. 36, No. 9, 1997, pp. 972-973. 